\title{
Growth in diagnosis and treatment of primary immunodeficiency within the global Jeffrey Modell Centers Network
}

\author{
Jessica Quinn, Vicki Modell, Jordan S. Orange and Fred Modell ${ }^{*}$ (D)
}

\begin{abstract}
Background: Primary immunodeficiencies (PI), which include more than 450 single-gene inborn errors of immunity and may affect up to $1 \%$ of the population, are genetic disorders that impair the immune system. If not properly identified and treated, individuals with PI are subject to serious, prolonged, and sometimes life-threatening infections or autoimmunity. Despite advancements, awareness of PI remains a critical issue for physicians and the public alike, as this leads to the enhanced and expedited management of these conditions. To address this critical issue, the Jeffrey Modell Foundation (JMF) formed a global network of specialized centers. The goal of this endeavor was to raise awareness of $\mathrm{PI}$ to better identify, diagnose, and treat patients, reducing associated mortality and morbidity and improving quality of life (QOL). For more than two decades, the Jeffrey Modell Centers Network (JMCN) has served as the foundation upon which these goals have been pursued. The JMCN currently includes 909 Expert Physicians at 400 institutions, in 316 cities, and 86 countries spanning six continents.
\end{abstract}

Methods: A survey was developed by JMF for members of the JMCN, following the most recent Classification of PI from the IUIS Expert Committee, to periodically describe the patient population, including treatment modalities and demographics. Physician-reported data from 2021 was compared to that from 2018 and 2013. Physicians in the JMCN also reported on select outcomes of their PI patients one year prior to and one year following diagnosis.

Results: A total of $300 \mathrm{JMF}$ Physician Surveys from 681 physicians were included in this analysis. This is a 75\% physician response rate. From 2013 to 2021, there was a 96.3\% increase in patients followed in the US and an 86.1\% increase globally. During the same period, patients identified with a specific Pl defect increased by $46.6 \%$ in the US and $47.9 \%$ globally. Patients receiving lgG and HSCT increased by $110 \%$ and $201 \%$ respectfully since 2013 . Early diagnosis led to reported decreased morbidity and mortality and reduced calculated healthcare costs.

Conclusions: This global analysis of physician-reported data on patients with PI demonstrates an increase in both diagnosed and treated patients. This substantial increase from within the JMCN is a testament to its impact. In addition to building an extensive global patient database, the expanding JMCN serves as a unique and critical resource, providing the infrastructure for earliest diagnosis, optimized treatments, and implementation of standard-ofcare and best practices. The JMCN provides a critical platform that facilitates the education of physicians and patients, awareness initiatives, and research advances, through collaboration and connectivity, ultimately resulting in improved outcomes and QOL for patients with PI. The JMCN has steadily and substantially grown for more than two decades and continues to substantively impact the field of Immunology globally.

*Correspondence: fmodell@jmfworld.org

Jeffrey Modell Foundation, 780 Third Avenue, 47th Floor, New York, NY

10017, USA original author(s) and the source, provide a link to the Creative Commons licence, and indicate if changes were made. The images or other third party material in this article are included in the article's Creative Commons licence, unless indicated otherwise in a credit line to the material. If material is not included in the article's Creative Commons licence and your intended use is not permitted by statutory regulation or exceeds the permitted use, you will need to obtain permission directly from the copyright holder. To view a copy of this licence, visit http://creativecommons.org/licenses/by/4.0/. The Creative Commons Public Domain Dedication waiver (http://creativeco mmons.org/publicdomain/zero/1.0/) applies to the data made available in this article, unless otherwise stated in a credit line to the data. 


\section{Key messages}

1. The JMCN has steadily and substantially grown for more than 2 decades and continues to significantly influence the global Immunology community.

2. In addition to compiling an extensive global patient database, the expanding JMCN acts as a unique and critical resource, increasing awareness of PIs, educating physicians and patients, and facilitating diagnosis via expertise and genetic sequencing, as well as treatment.

3. The JMCN provides a platform to optimize research advances, earliest diagnosis, enhanced treatments, and implement standard-of-care and best practices through maximized connectivity, resulting in a better quality of life and improved outcomes for patients with PI.

Keywords: Primary immunodeficiency (PI), Jeffrey Modell Foundation (JMF), Jeffrey Modell Centers Network (JMCN), Network, Awareness, Education, Diagnosis, Treatment, Immunology

\section{Introduction}

Primary immunodeficiencies (PI), which include over 450 single-gene inborn errors of immunity (IEI), are genetic disorders that impair the immune system [1-3]. Individuals with PI are subject to serious, prolonged, and sometimes life-threatening infections and autoimmunity when not properly identified and treated [1, 4-7]. Manifestations of PI can range from life-threatening, such as Severe Combined Immunodeficiency (SCID), to vulnerability to common and opportunistic infections, persistent inflammation, and autoimmunity. Up to $1 \%$ of the global population may have a PI when all IEIs are considered, which is more than previously predicted $[2$, $8,9]$.

Despite advancements in research, genetic sequencing, molecular diagnosis, and treatments that increased our grasp of the immune system and bettered quality of life (QOL) for individuals with PI, awareness of PI remains a critical issue for physicians and the public alike. Increasing awareness of PI leads to the enhanced and expedited management of these conditions [10-16].

To address this critical issue, the Jeffrey Modell Foundation (JMF) formed a global network of specialized centers and developed JMF's 10 Warning Signs of PI (Figs. 1, 2). The goal of this endeavor was to raise awareness of PI to better identify, diagnose, and treat patients, provide tools useful in these endeavors, and ultimately reduce associated mortality and morbidity and improve QOL. For more than two decades, the Jeffrey Modell Centers Network (JMCN) has laid the groundwork to accomplish these goals, with 909 Expert Physicians at 400 institutions, in 316 cities and 86 countries spanning six continents. A list of expert physicians in the JMCN is shared, with permission, on JMF's website through the "Find an Expert" tool, which can be accessed at http://info4pi.org/information-booth/ find-an-expert. The network is continually expanding, with growth each year, further highlighting its influence over the past two decades as a sought-after resource for the PI community.

A detailed survey for members of the JMCN was developed by JMF, following the most recent Classification of PI from the International Union of Immunological Societies (IUIS) Expert Committee [17, 18], to periodically report on the PI patient population, including treatments utilized and demographics (Additional file 1: Figure S1). Additional objectives of the survey were to provide meaningful information to quantify and evaluate the effectiveness and ultimate health impact of JMF's awareness and advocacy activities, to assess the growth of the patient population, to assess treatment modalities, to identify any notable changes or patterns, and to provide periodic comprehensive reports to the JMCN and broader PI community. The IUIS classification is an invaluable resource for immunologists and researchers everywhere and currently includes 416 distinct disorders with nearly 450 different gene defects listed [17]. In the past two years, 64 new gene defects were either discovered or confirmed [17], due in part to the increased use of exome sequencing (ES) and next generation sequencing (NGS). Several of these new IEI have been found in either an individual or a just a few kindreds, which may not offer a comprehensive description of prevalence and phenotype [17]. Further complicating accurate diagnosis, is the considerable expansion of phenotypes associated with specific diseases and gene variants of uncertain significance, both associated with the increased use and accessibility of NGS [17].

\section{Methods \\ Growth of the JMCN}

The JMCN is currently made up of 909 expert physicians at 400 institutions, in 316 cities, and 86 countries across 6 


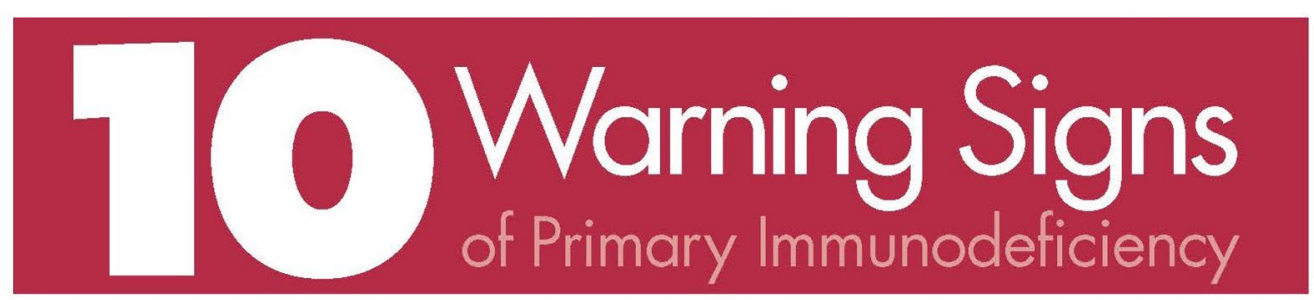

Primary Immunodeficiency (PI) causes children and adults to have infections that come back frequently or are unusually hard to cure. 1:500 persons are affected by one of the known Primary Immunodeficiencies. If you or someone you know is affected by two or more of the following Warning Signs, speak to a physician about the possible presence of an underlying Primary Immunodeficiency.

1 Four or more new ear infections within 1 year.

2 Two or more serious sinus infections within 1 year.

3 Two or more months on antibiotics with little effect.

4 Two or more pneumonias within 1 year.

5 Failure of an infant to gain weight or grow normally.

6 Recurrent, deep skin or organ abscesses.

7 Persistent thrush in mouth or fungal infection on skin.

8 Need for intravenous antibiotics to clear infections.

- Two or more deep-seated infections including septicemia.

10 A family history of PI.

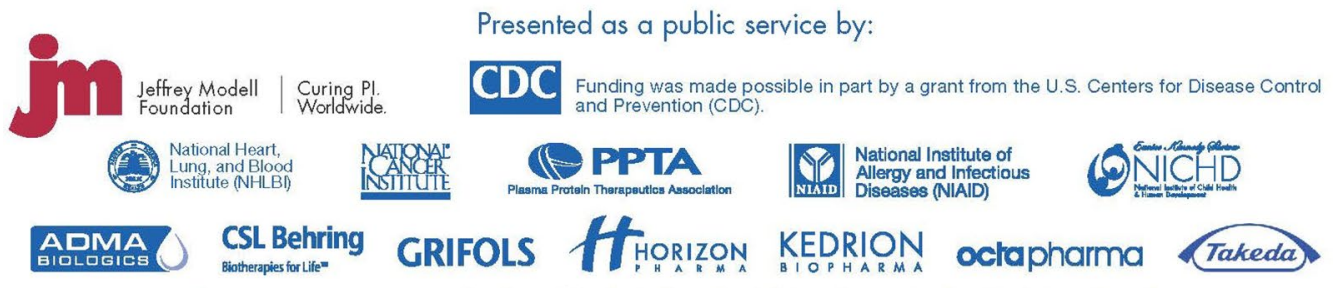

These warning signs were developed by the Jeffrey Modell Foundation Medical Advisory Board. Consultation with Primary Immunodeficiency experts is strongly suggested. (c) 2021 Jeffrey Modell Foundation For information or referrals, contact the Jeffrey Modell Foundation: info4pi.org

Fig. 1 JMF's 10 warning signs of PI

continents, and is always growing as physicians seek to be included. A comprehensive catalog of all JMCN members and their affiliated centers is maintained and updated on a regular basis, as expert immunologists join or leave the network (due to retirement, relocation, change in employment, etc.). The current make-up of the JMCN was compared to that from 2018 and 2013, which has been previously published $[19,20]$.

\section{JMF Physician Survey}

The JMF Physician Survey follows the most recent version of the Classification of PI from the IUIS Expert 


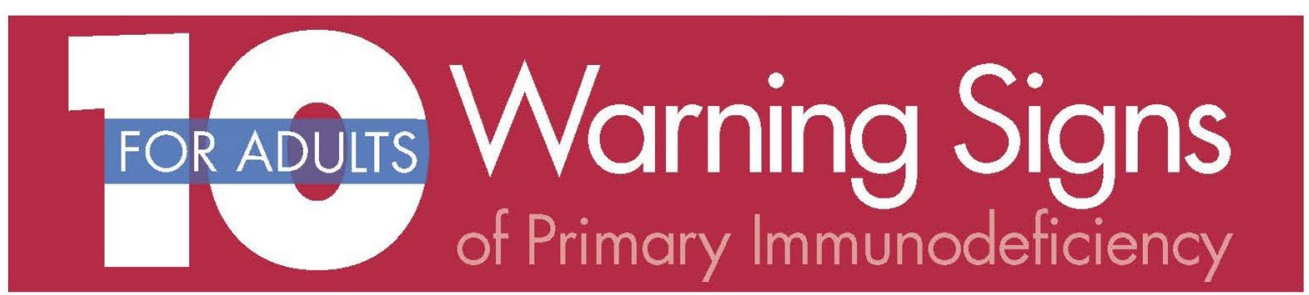

Primary Immunodeficiency (PI) causes children and adults to have infections that come back frequently or are unusually hard to cure. 1:500 persons are affected by one of the known Primary Immunodeficiencies. If you or someone you know is affected by two or more of the following Warning Signs, speak to a physician about the possible presence of an underlying Primary Immunodeficiency.

1 Two or more new ear infections within 1 year.

2 Two or more new sinus infections within 1 year, in the absence of allergy.

3 One pneumonia per year for more than 1 year.

4 Chronic diarrhea with weight loss.

5 Recurrent viral infections (colds, herpes, warts, condyloma).

6 Recurrent need for intravenous antibiotics to clear infections.

7 Recurrent, deep abscesses of the skin or internal organs.

8 Persistent thrush or fungal infection on skin or elsewhere.

- Infection with normally harmless tuberculosistike bacteria.

10 A family history of PI.

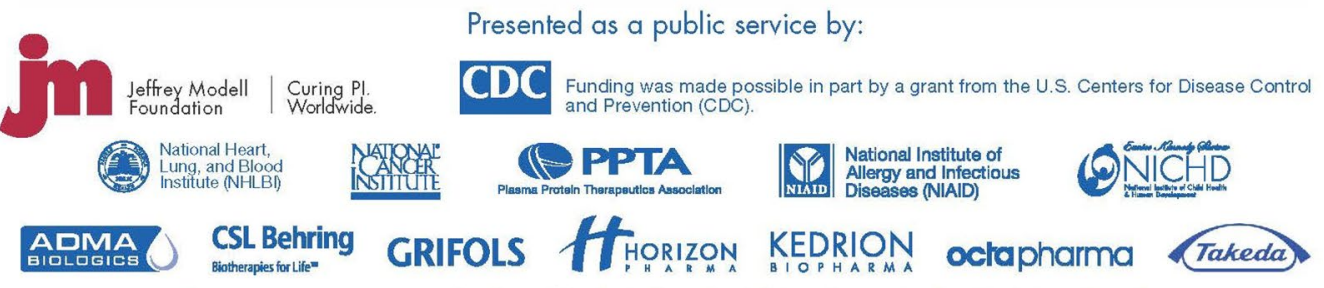

These warning signs were developed by the Jeffrey Modell Foundation Medical Advisory Board. Consultation with Primary Immunodeficiency experts is strongly suggested. (c) 2021 Jeffrey Modell Foundation For information or referrals, contact the Jeffrey Modell Foundation: info4pi.org

Fig. 2 JMF's adult 10 warning signs of $\mathrm{PI}$

Committee available at the time $[17,18]$ (and before the most recent interim update) [3] and lists the Online Mendelian Inheritance in Man (OMIM) number for each defect or gene, if available. When appropriate, the inheritance and mutation type is provided for each gene, as per the IUIS document.
The 2020-2021 survey, which adheres to the latest IUIS classification tables, requested information on patients followed and diagnosed with a PI. A section was provided to list any genes or disorders not listed in the survey tables. The survey also requested information on the administration of immunoglobulin therapies, 
hematopoietic stem cell transplantation (HSCT), and gene therapy. Additionally, a demographics section was provided requesting information regarding gender and age.

Surveys were sent via email to the entire JMCN, requesting information in 2020-2021, and were sent back to JMF by email or fax. Importantly, all information provided was HIPAA compliant and no identifying information was obtained. The 2021 physician-reported data was then compared to that from 2018 and 2013, which was obtained in a similar manner and format and has been previously published $[19,20]$.

\section{Clinical outcomes and cost analysis}

We asked physicians in the JMCN to report on outcomes of their PI patients one year prior to and one year following diagnosis including the number of episodes of specific infections, days in the hospital, ER and office visits, days on medication, and missed school or workdays. These findings should be considered as physician-reported and directional since validation of outcomes was not mandatory.

The cost per episode for specific conditions was determined using the Agency for Healthcare Research Quality (AHRQ) Medical Expenditure Panel Survey (MEPS), which provides data on health care utilization and expenditures by medical condition [21]. The cost of hospitalization per day was obtained from the Kaiser Family Foundation report on the American Hospital Association (AHA) annual survey [22]. The associated costs of physician visits, emergency room visits, and antibiotic treatment were acquired from the Health Care Cost Institute (HCCI) 2018 Health Care Cost and Utilization Report, which utilizes data from 40 million enrollees of employer-sponsored health insurance annually between 2014 and 2018 [23]. The costs associated with missed days of work were derived from the United States Social Security Administration [24]. Additional and supporting data were obtained from the Hospital Cost and Utilization Project (HCUP) [25]. HCUP offers the largest inpatient care database in the US, including more than 7 million hospital stays, allowing for examination of special populations, uncommon treatments, and rare conditions [25]. Given the sources used, however, it should be assumed that the costs estimated are more specific to those found in the US and may be distinct from those encountered in other countries.

\section{Statistical analysis}

Responses were recorded in a secure Microsoft Excel spreadsheet, with quality control measures in place to maximize the quality of data entry. Data fields corresponded with those of the 2020-2021 survey (Additional file 1: Figure S1). Descriptive quantitative statistical analyses were performed to summarize the responses including the distribution, percent change, prevalence, and mean, each when appropriate. Differences between select geographical areas were examined, as well as between select years. Regarding missing values, there were many ranging from 0 to $97.3 \%$ (Additional file 2: Table S1), depending upon field and question, based on 300 surveys received $(n=300)$. Due to the survey design and instructions, for all fields other than demographics, a missing response was interpreted as a "zero" in that the physician did not have any patients having that particular condition or receiving that particular treatment. For the demographic fields, analysis was performed only for the available data, as the missing values do not relate to any of the other data fields.

\section{Results \\ Growth of the JMCN}

The JMCN is made up of 909 expert physicians at 400 institutions, in 316 cities, and 86 countries across 6 continents. Since 2013, the number of institutions, cities, and physicians included in the network have increased by $70.9 \%, 61.2 \%$, and $63.5 \%$, respectively (Fig. 3). A total of 300 JMF Physician Surveys from 681 physicians were included in this analysis, representing 80 countries, 227 cities, and 280 institutions. This is a $75 \%$ physician response rate. Nearly $30 \%$ of reporting physicians were located in the US, representing 32 states. The number of reporting Centers, reporting physicians, and surveys received increased by $16.2 \%, 30.5 \%$, and $33.9 \%$ respectively from 2013 to 2021 (Fig. 4). Thus, at a minimum, the increase in any category between 2013 and 2021 that was over $34 \%$ is unlikely to have resulted from simply an increase in responses. That said, since most of the largest centers were part of the JMCN in

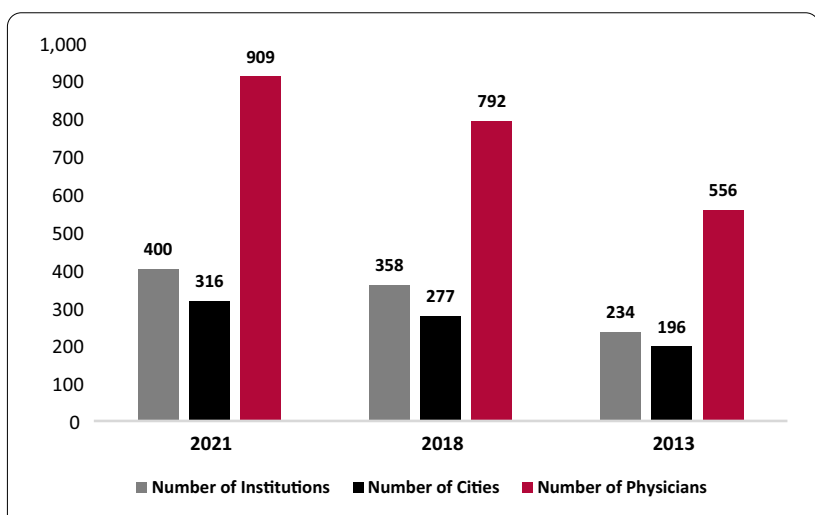

Fig. 3 Growth of the Jeffrey Modell Centers Network (JMCN) 


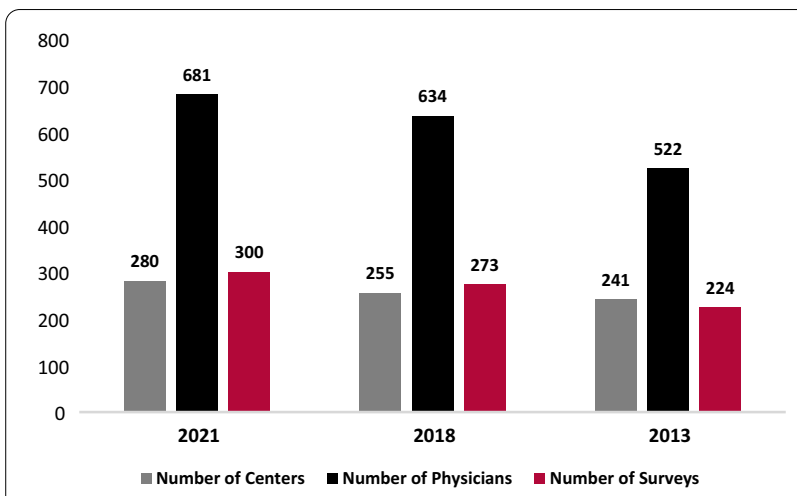

Fig. 4 Reports received from the JMCN

2013 that percentage expectation should be considered conservative.

\section{Prevalence}

Physician-reported prevalence of patients with PI increased from 2013 to 2021, with a $96.3 \%$ increase in patients followed in the US and an $86.1 \%$ increase globally (Fig. 5). During the same period, patients identified with a specific PI defect increased by $46.6 \%$ in the US and 47.9\% globally (Fig. 6). "International" includes all reports except the US, while "Global" includes all reports. Given an increase of $16.2 \%$ in sites reporting during this period, the increase in prevalence and other reported measures were unlikely due to an increase in reporting centers alone, and so the data presented were not normalized.

From 2013 to 2021, total patients followed, and total patients identified with a specific PI defect were compared across nine geographical regions. Total patients followed increased across all nine geographical regions, with an increase of $34.1 \%$ in Canada, $128 \%$ in Latin America, $140.5 \%$ in Western Europe, $28.9 \%$ in Eastern Europe, 78\% in the Middle East, $53.5 \%$ in Asia, 2,073.6\% in Australia, and 98.6\% in Africa (Table 1). Total patients identified with a specific PI defect increased by

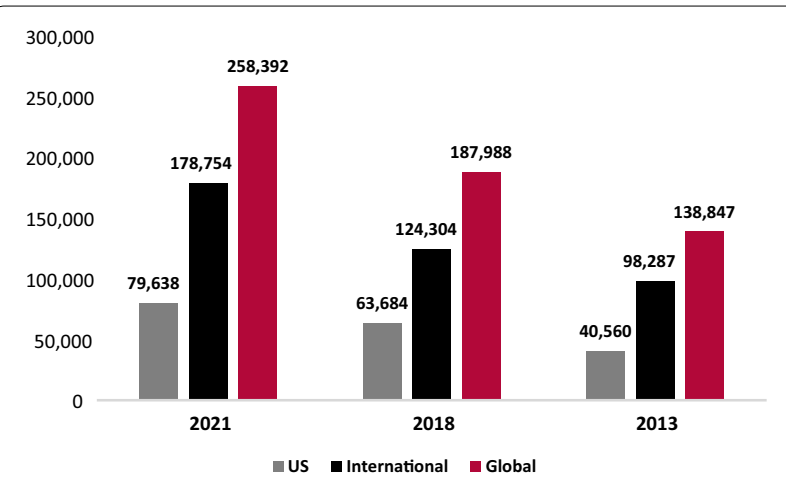

Fig. 5 Physician-reported prevalence of PI: patients followed

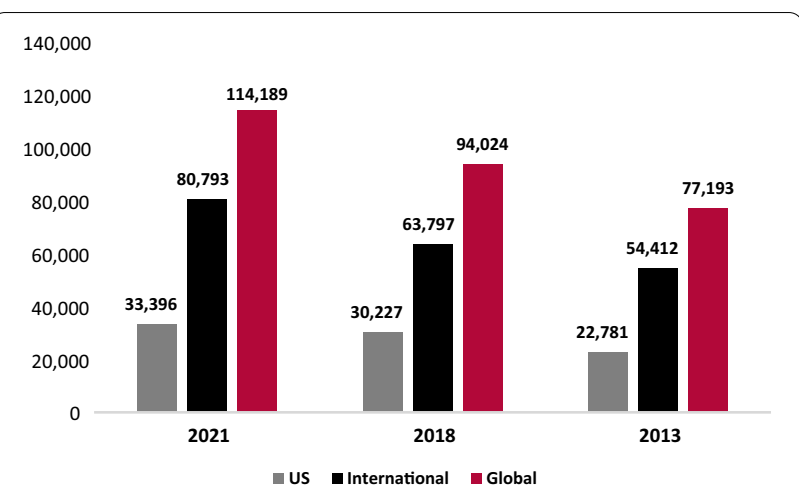

Fig. 6 Physician-reported prevalence of PI: patients identified with Pl defects

77.8\% in Latin America, 45.2\% in Western Europe, 25.7\% in Eastern Europe, $92.4 \%$ in the Middle East, $128.5 \%$ in Asia, 22.5\% in Africa, and 1,873.6\% in Australia (Table 1). Importantly, during this period, there was a substantial increase in reporting sites in Latin America, but this only explains a fraction of the growth in patients. In the US, Canada, Western Europe, Eastern Europe, Asia, and Australia there was a slight increase in reporting sites. In the Middle East, there was a minor decrease in reporting sites, while in Africa, reporting sites remained stable.

\section{IUIS classification}

The 2021 patient distribution according to the IUIS classification of PI categories was examined in the US, internationally, and globally. Physicians reported that Predominantly Antibody Deficiencies accounted for $56 \%$ of patients with a specific PI defect in the US, $37 \%$ internationally, and $42 \%$ globally (Table 2). Combined Immunodeficiencies with Associated Syndromic Features accounted for $17 \%$ of patients with a specific PI defect in the US, $11 \%$ internationally, and $12 \%$ globally. Unspecified or Other Deficiencies accounted for $9 \%$ of these patients in the US, $12 \%$ internationally, and $11 \%$ globally; a $4 \%$ reduction since 2018 . Figure 7 shows the change in physician-reported prevalence of PI by the IUIS diagnostic category from 2013 to 2021.

The fifteen most prevalent PI defects were examined by geographical region. The most prevalent was Common Variable Immunodeficiency (CVID), with $16.6 \%$ in the US, $12.9 \%$ internationally, and $13.9 \%$ globally (Table 3 ). Specifically, for CVID, Canada had a $22.5 \%$ prevalence while Australia had a $34.2 \%$ prevalence. There was a prevalence of $10.8 \%$ for Selective IgA Deficiency in the US, $9.9 \%$ internationally, and $10.2 \%$ globally. The Middle East reported a prevalence of 19.2\% Familial Mediterranean Fever compared to a $2.2 \%$ prevalence globally, and Africa reported a 7\% prevalence of Ataxia 
Table 1 Physician-reported prevalence of PI by region

\begin{tabular}{|c|c|c|c|c|c|c|c|c|}
\hline & \multicolumn{4}{|c|}{ Patients followed } & \multicolumn{4}{|c|}{ Patients identified $w / P I$ defects } \\
\hline & 2021 & 2018 & 2013 & $\%$ Change (\%) & 2021 & 2018 & 2013 & $\%$ change $(\%)$ \\
\hline US & 79,638 & 63,684 & 40,560 & 96.3 & 33,396 & 30,227 & 22,781 & 46.6 \\
\hline Canada & 5440 & 4923 & 4058 & 34.1 & 3078 & 3047 & 3880 & -20.7 \\
\hline Latin America & 12,257 & 12,487 & 5377 & 128.0 & 9531 & 8793 & 5361 & 77.8 \\
\hline Western Europe & 86,399 & 46,011 & 35,932 & 140.5 & 37,040 & 28,592 & 25,518 & 45.2 \\
\hline Eastern Europe & 54,743 & 47,525 & 42,458 & 28.9 & 14,936 & 11,631 & 11,886 & 25.7 \\
\hline Middle East & 9823 & 7155 & 5520 & 78.0 & 8408 & 5664 & 4370 & 92.4 \\
\hline Asia & 5178 & 2581 & 3373 & 53.5 & 4212 & 2358 & 1843 & 128.5 \\
\hline Australia & 1978 & 1927 & 91 & 2073.6 & 1796 & 1876 & 91 & 1873.6 \\
\hline Africa & 2936 & 1695 & 1478 & 98.6 & 1792 & 1836 & 1463 & 22.5 \\
\hline Total & 258,392 & 187,988 & 138,847 & 86.1 & 114,189 & 94,024 & 77,193 & 47.9 \\
\hline
\end{tabular}

The number of patients followed and identified with a specific PI defect by region in 2021, 2018, and 2013

Table 2 Physician-reported prevalence of PI by classification, 2021

\begin{tabular}{|c|c|c|c|}
\hline & US & INT'L & Global \\
\hline Immunodeficiencies affecting cellular and humoral immunity & 1566 & 5985 & 7551 \\
\hline Combined immunodeficiencies with associated syndromic features & 5677 & 10,892 & 16,569 \\
\hline Predominantly antibody deficiencies & 19,423 & 37,418 & 56,841 \\
\hline Diseases of immune dysregulation & 1199 & 3676 & 4875 \\
\hline Congenital defects of phagocyte number or function & 1678 & 17,332 & 19,010 \\
\hline Defects in intrinsic and innate immunity & 311 & 1993 & 2304 \\
\hline Autoinflammatory disorders & 673 & 6328 & 7001 \\
\hline Complement deficiencies & 646 & 4418 & 5064 \\
\hline Bone marrow failure & 58 & 306 & 364 \\
\hline Phenocopies of inborn errors of immunity & 48 & 286 & 334 \\
\hline Unspecified or other deficiencies & 3135 & 12,362 & 15,497 \\
\hline Total $^{\mathrm{a}}$ & 34,414 & 100,996 & 135,410 \\
\hline
\end{tabular}

The 2021 distribution of patients according to the IUIS classification of PI categories

a Global total doesn't match Table 1 due to the inclusion of "Unspecified or Other Deficiencies" and reporting

Telangiectasia compared to a $2.7 \%$ prevalence globally. The fifteen most prevalent PI defects have remained quite consistent over the past eight years, with only minor differences, potentially due to modifications in classification. Figure 8 shows the change in physicianreported prevalence of 10 PI defects from 2013 to 2021.

\section{Treatment}

Immunoglobulin therapies were examined from 2013 to 2021. According to physician reports, since 2013, patients receiving IgG increased by $110 \%$ (Table 4). A total of $32 \%$ of all patients with a PI defect receive immunoglobulin replacement therapy. Patients receiving subcutaneous immunoglobulin (SCIG) increased by 378\% since 2013 and patients getting Intravenous immunoglobulin therapy (IVIG) in the hospital or clinic increased by $114.4 \%$. There was a $22.2 \%$ decrease in patients getting
IVIG at home during this period, however a $378 \%$ increase in patients getting SCIG more than compensates for this decrease.

Immunoglobulin therapies in 2021 were examined in nine geographical regions. Notably, $53 \%$ of patients treated with IgG in Western Europe receive SCIG compared to $37.5 \%$ globally, and $75 \%$ of patients getting IgG in Latin America are treated in the clinic or hospital compared to $52.4 \%$ globally (Table 5). Additionally, $24.5 \%$ of patients getting IgG in the US, do so at home compared to $9.2 \%$ globally.

From 2013 to 2021, treatment with immunoglobulin therapy was examined in nine geographical regions. A $110 \%$ global rise in the number of patients receiving IgG was seen during this period, even with just a $16.2 \%$ increase in reporting centers. However, a rise in reporting Centers in Latin America likely resulted in the substantial 
60,000

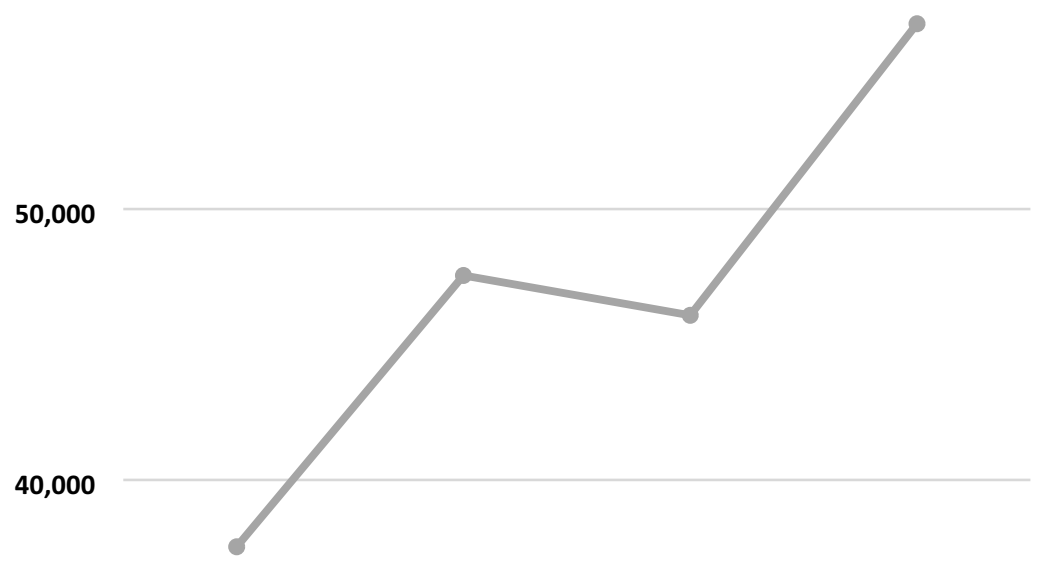

30,000

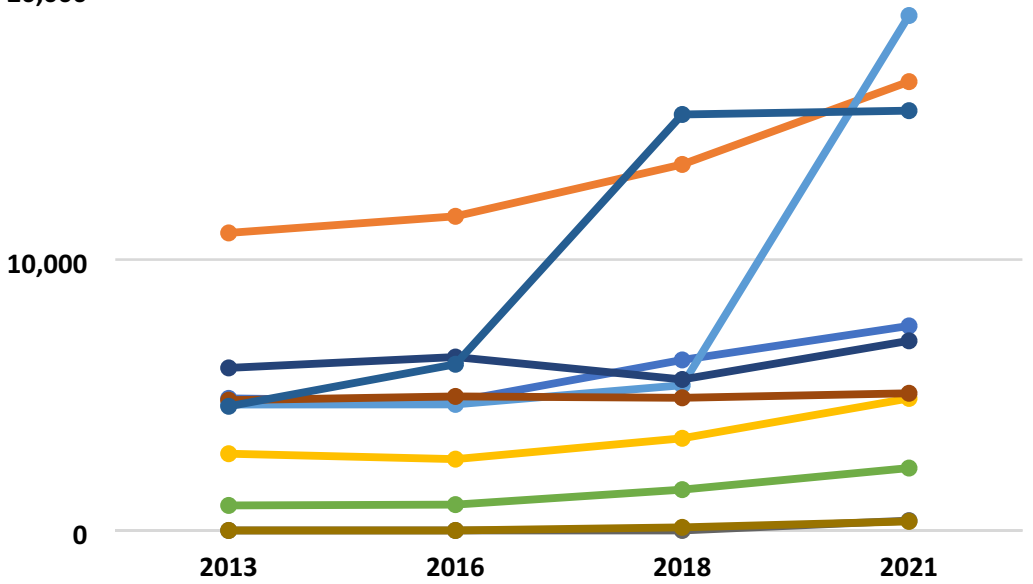

-Immunodeficiencies Affecting Cellular and Humoral Immunity

$\longrightarrow$ Combined

Immunodeficiencies with Associated Syndromic Features

-Predominantly

Antibody

Deficiencies

Diseases of Immune Dysregulation
Congenital Defects of Phagocyte Number or Function

Defects in Intrinsic and Innate Immunity

Autoinflammatory Disorders

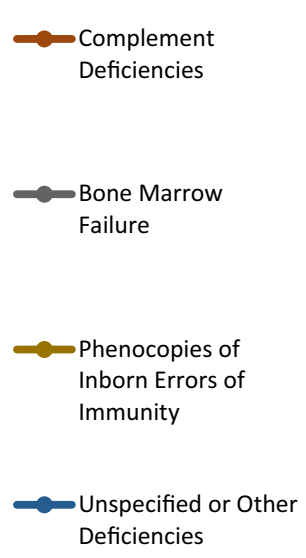

Fig. 7 Physician-reported prevalence of PI by IUIS classification, 2013-2021

growth in patients receiving IgG reported in that region (Table 6).

In addition to treatment with immunoglobulin therapy, additional treatments were assessed, such as HSCT, PEGADA, and gene therapy. There was substantial growth in patients obtaining these treatments for PI, with the most patients receiving $\mathrm{HSCT}$, then gene therapy and PEGADA (Table 7). These treatment methods were examined in nine geographical regions in 2021. Gene therapy was reported in the greatest number of patients in Western Europe.

As practices in HSCT have been evolving, greater detail in the use of this treatment was pursued. For patients reported to receive $\mathrm{HSCT}$, stem cell donor type was assessed from 2013 to 2021. The number of patients treated by HSCT increased by $201 \%$. 


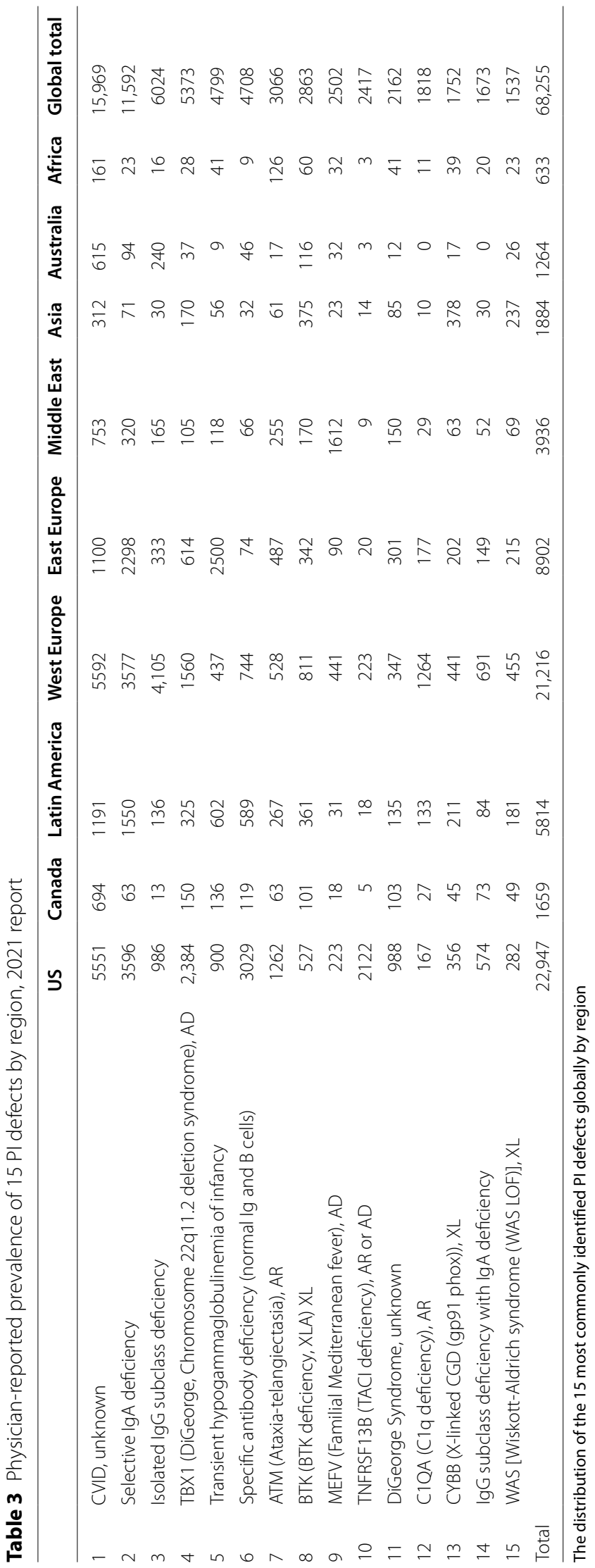




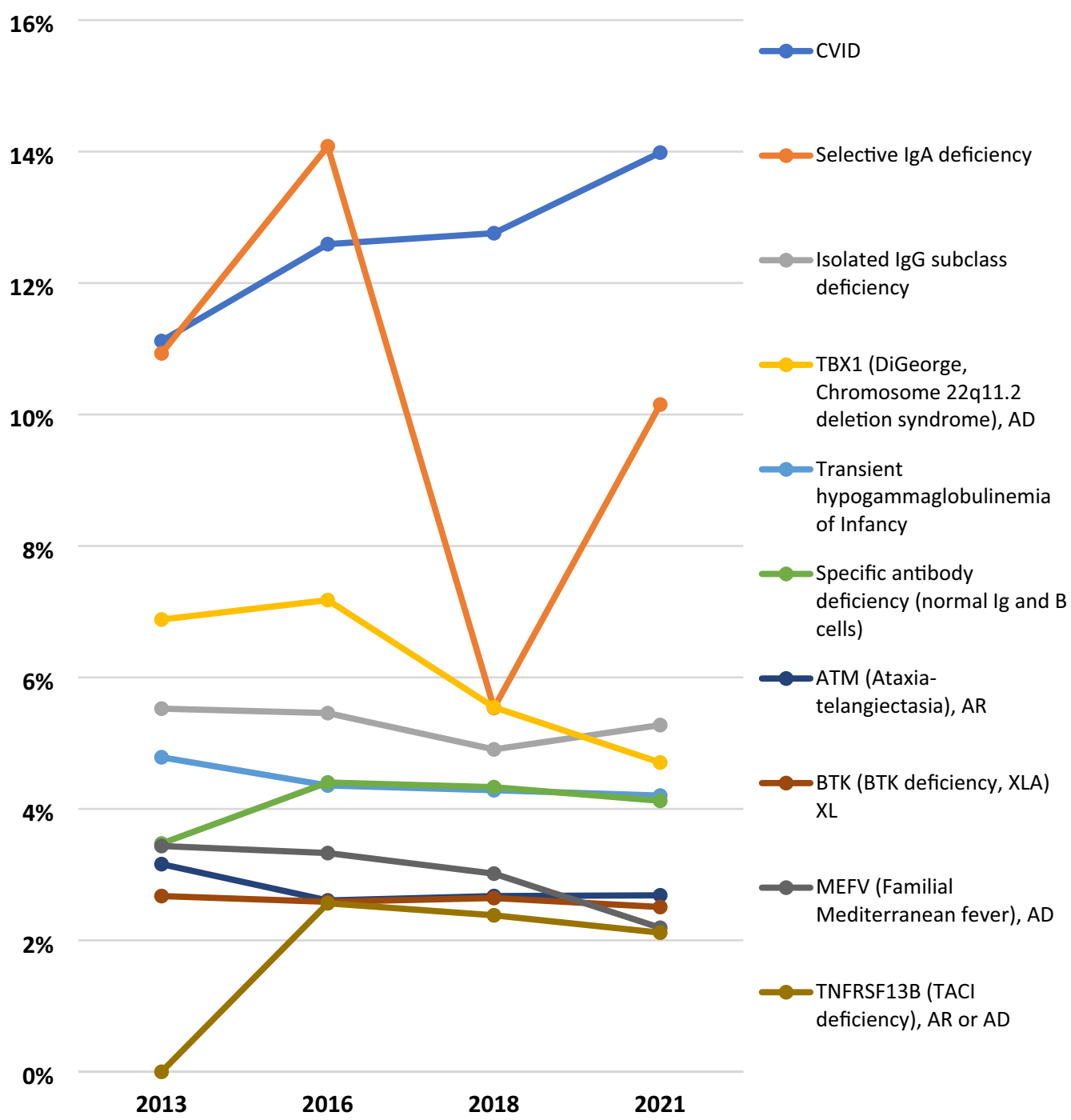

Fig. 8 Physician-reported prevalence of the 10 most commonly identified PI defects, 2013-2021

Further, there was a $249 \%$ increase in matched donor transplants, a $190 \%$ increase in matched unrelated donor transplants, a $183 \%$ increase in mismatched unrelated donor transplants, and a $162 \%$ increase in parental haplo transplants (Table 8). Stem cell donor type was examined in nine geographical regions in 2021. The most common stem cell donor type globally was matched unrelated, followed by matched related (Table 9). In the Middle East, Africa, and Eastern Europe matched related was the most common stem cell donor type. In Western Europe and Australia, parental haploidentical transplants accounted for $28 \%$ of HSCT, markedly more than the other regions.

For patients receiving HSCT, the stem cell source was assessed from 2013 to 2021. There was a $224.2 \%$ increase in bone marrow as the stem cell source and a $248.7 \%$ increase in cord blood (Table 10). Stem cell source in 2021 was examined in nine geographical regions and varied significantly by region. It was reported that $56.9 \%$ of transplants in Latin America used bone marrow, compared to $61 \%$ globally (Table 11). In the Middle East, $36.3 \%$ of transplants used peripheral stem cells, compared to $24.4 \%$ globally, and $35.6 \%$ of the transplants used cord blood in Asia, compared to $12 \%$ globally.

The substantial growth described above is partially due to newborn screening, molecular diagnosis, and NGS, and may need additional evaluation in the future. Notably, some Centers did not report treatment data, 
Table 4 Treatment with lgG by site of care

\begin{tabular}{lrrrc}
\hline & $\mathbf{2 0 2 1}$ & $\mathbf{2 0 1 8}$ & $\mathbf{2 0 1 3}$ & \% change (\%) \\
\hline IVIG_clinic & & & & \\
US & 3604 & 3299 & 2572 & 40.1 \\
INT'L & 15,385 & 9296 & 6285 & 144.8 \\
Global & 18,989 & 12,595 & 8857 & 114.4 \\
IVIG_home & & & & \\
US & 2449 & 2381 & 2423 & 1.1 \\
INT'L & 895 & 842 & 418 & 114.1 \\
Global & 3344 & 3223 & 4298 & -22.2 \\
SCIG & & & & \\
US & 3822 & 2881 & 1631 & 134.3 \\
INT'L & 9759 & 4778 & 2667 & 265.9 \\
Global & 13,581 & 7659 & 2841 & 378.0 \\
Total, including "other" & & & \\
US & 9984 & 8721 & 7315 & 36.5 \\
INT'L & 26,186 & 15,246 & 9910 & 164.2 \\
Global & 36,170 & 23,967 & 17,225 & 110.0 \\
\hline
\end{tabular}

The number of patients reported to receive immunoglobulin therapy (IgG) intravenously in the clinic and at home, subcutaneously, and by other treatment modalities in 2021, 2018, and 2013

potentially due to access issues, data availability, or specific hospital guidelines.

\section{Demographics}

Physician-reported patient demographics in 2021 were compared with that of 2018 and 2013. Reports included information on gender for 62,045 patients and on age for 56,187 patients (Table 12 ). Of these patients, $58 \%$ were male and $42 \%$ were female, globally. In the US alone, $56.3 \%$ were male, and $43.7 \%$ were female. It was reported that $64.2 \%$ of these patients were $0-19$ years old, and $35.8 \%$ were $20+$ years old, globally. The demographic distribution has largely remained consistent since 2013.

\section{Clinical outcomes and cost analysis}

Physicians in the JMCN reported on outcomes of their PI patients 1 -year pre and 1 year post diagnosis, including episodes of specific infections, days in the hospital, ER
Table 6 Treatment with lgG by region

\begin{tabular}{lrrrc}
\hline & $\mathbf{2 0 2 1}$ & $\mathbf{2 0 1 8}$ & $\mathbf{2 0 1 3}$ & \% change (\%) \\
\hline US & 9984 & 8721 & 7315 & 36.5 \\
Canada & 1251 & 1113 & 756 & 65.5 \\
Latin America & 3104 & 1901 & 851 & 264.7 \\
Western Europe & 13,957 & 7375 & 5343 & 161.2 \\
Eastern Europe & 3402 & 2205 & 1675 & 103.1 \\
Middle East & 2021 & 739 & 485 & 316.7 \\
Asia & 730 & 391 & 322 & 126.7 \\
Australia & 1180 & 1125 & 21 & 5519.0 \\
Africa & 541 & 397 & 457 & 18.4 \\
Total & 36,170 & 23,967 & 17,225 & 110.0 \\
\hline
\end{tabular}

The number of patients reported to receive IgG by region in 2021,2018, and 2013

and office visits, days on certain medications, and missed school or workdays. For each condition analyzed, the average number of reported episodes decreased after diagnosis, as did the number of hospital days, ER and office visits, days on antibiotics, and missed school or workdays, resulting in overall decreased morbidity and mortality. Importantly, early diagnosis also reduced estimated healthcare costs (using US cost bases), even with routine IgG replacement therapy (Table 13). Each diagnosed patient translated to a $\$ 97,488$ annual savings to the healthcare system. The savings remain at $\$ 87,888$ annually, even for diagnosed patients treated with IgG.

\section{Discussion}

The JMCN

The JMCN was developed by JMF to meet the rising need for specialized centers to accommodate the increasing patient population and to create the infrastructure needed to promote research, early diagnosis, and proper treatment. Physicians in the JMCN have reported continued growth in the identification, diagnosis, and treatment of patients with PI in the twenty years since the JMCN was

Table 5 Treatment with lgG by site of care by region

\begin{tabular}{|c|c|c|c|c|c|c|c|c|c|c|}
\hline & US & Canada & Latin America & West Europe & East Europe & Middle East & Asia & Australia & Africa & Global totals \\
\hline IVIG_clinic & 3604 & 717 & 2327 & 5646 & 2472 & 1981 & 703 & 1042 & 497 & 18,989 \\
\hline IVIG_home & 2449 & 11 & 67 & 814 & 0 & 1 & 0 & 1 & 1 & 3344 \\
\hline $\mathrm{SClG}$ & 3822 & 523 & 636 & 7450 & 927 & 24 & 27 & 136 & 36 & 13,581 \\
\hline Other & 109 & 0 & 74 & 47 & 3 & 15 & 0 & 1 & 7 & 256 \\
\hline Totals & 9984 & 1251 & 3104 & 13,957 & 3402 & 2021 & 730 & 1180 & 541 & 36,170 \\
\hline
\end{tabular}

The number of patients reported to receive lgG intravenously in the clinic and at home, subcutaneously, and by other treatment modalities by region, 2021 


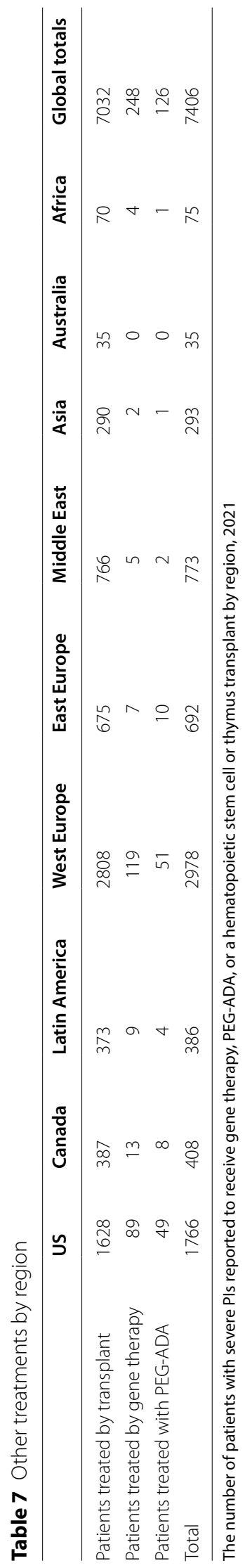


Table 8 Stem cell donor type used for patients having received HSCT

\begin{tabular}{lrrrl}
\hline & $\mathbf{2 0 2 1}$ & $\mathbf{2 0 1 8}$ & $\mathbf{2 0 1 3}$ & \% change (\%) \\
\hline MRD & & & & \\
US & 290 & 229 & 76 & 281.6 \\
INT'L & 1624 & 1103 & 472 & 244.1 \\
Global & 1914 & 1332 & 548 & 249.3 \\
MUD & & & & \\
US & 535 & 362 & 151 & 254.3 \\
INT'L & 1483 & 1162 & 544 & 172.6 \\
Global & 2018 & 1524 & 695 & 190.4 \\
mMUD & & & & \\
US & 160 & 138 & 29 & 451.7 \\
INT'L & 302 & 211 & 134 & 125.4 \\
Global & 462 & 349 & 163 & 183.4 \\
Parental haplo & & & & \\
US & 218 & 126 & 57 & 282.5 \\
INT'L & 906 & 727 & 372 & 143.5 \\
Global & 1124 & 853 & 429 & 162.0 \\
Total & & & & \\
US & 1203 & 855 & 313 & 284.3 \\
INT'L & 4315 & 3203 & 1522 & 183.5 \\
Global & 5518 & 4058 & 1835 & 200.7 \\
\hline
\end{tabular}

The number of patients reported to receive HSCT from matched related donors, matched unrelated donors, mismatched unrelated donors, and parental donors in 2021,2018 , and 2013

established and education and awareness initiatives were introduced. The JMCN is continuously expanding, and patients with PI are increasingly being identified within the network and in general [26], allowing them to receive earlier diagnosis and appropriate treatment, leading to improved outcomes and QOL.

This comprehensive global analysis of physicianreported data on patients with PI demonstrates an increase in diagnosed and treated patients that generally outpaces any overall increase in surveys returned to JMF. The considerable growth in patients can likely be attributed to newborn screening, education and awareness activities, molecular diagnosis, and increased availability of genetic diagnostics including NGS platforms. There continue to be notable regional differences within the JMCN, likely due to founder effects and consanguinity increasing the prevalence of certain defects $[15,27]$. This should inform future awareness campaigns, which can be developed to address the unique needs of each geographical region. Efforts, such as continuing medical education, can be focused and tailored to identify risk categories more accurately through further assessment of specific genes. Opportunities for targeted education and resourcing should be enhanced to embolden experts who can truly impact outcomes for patients with PI to hopefully save lives.

Although the reported proportion of patients found with a specific defect has decreased by about $10 \%$ over the previous eight years, there was an overall increase in patients reported and a $4 \%$ total reduction in patients reported with an unspecified defect, since 2018. The recent less dramatic rise in patients found with a specific defect is likely a consequence of the JMCN continuously expanding into regions with limited to no access to molecular diagnosis and genetic sequencing. Although patients with PI are being identified at an increasingly higher rate and there are meaningful advancements in genomic technologies underway, further improvements need to be made.

Additionally, a limitation of this analysis is the presence of missing responses. To mitigate this limitation and reduce missing responses in the future, serious consideration is being given to transitioning to the use of electronic forms with each field requiring a response within a specified range when appropriate.

\section{Clinical outcomes and cost analysis}

Over the previous few decades, there has been a drastic improvement in patient outcomes across the spectrum of PI diagnoses due to early recognition [28-30]. In addition to the seemingly obvious improvements in outcomes for patients, early recognition of PI results in annual estimated savings to the healthcare system (US-based) for each diagnosed patient of $\$ 97,488$. Even when

Table 9 Stem cell donor type used for patients having received HSCT by region

\begin{tabular}{lcccccccccc}
\hline Donor type & US & Canada & Latin America & West Europe & East Europe & Middle East & Asia & Australia & Africa & Global totals \\
\hline MRD & 290 & 91 & 108 & 623 & 284 & 398 & 68 & 7 & 45 & 1914 \\
MUD & 535 & 239 & 123 & 666 & 276 & 46 & 100 & 21 & 12 & 2018 \\
mMUD & 160 & 31 & 13 & 199 & 7 & 30 & 22 & 0 & 0 & 462 \\
Parental haplo & 218 & 20 & 83 & 577 & 71 & 79 & 52 & 11 & 13 & 1124 \\
Totals & 1203 & 381 & 327 & 2065 & 638 & 553 & 242 & 39 & 70 & 5518 \\
\hline
\end{tabular}

The number of patients reported to receive HSCT from matched related donors, matched unrelated donors, mismatched unrelated donors, and parental donors by region, 2021 
Table 10 Stem cell source used for patients having received HSCT

\begin{tabular}{lrrrl}
\hline & $\mathbf{2 0 2 1}$ & $\mathbf{2 0 1 8}$ & $\mathbf{2 0 1 3}$ & \% change (\%) \\
\hline Bone marrow & & & & \\
US & 794 & 585 & 189 & 320.1 \\
INT'L & 2539 & 1953 & 839 & 202.6 \\
Global & 3333 & 2538 & 1028 & 224.2 \\
Peripheral stem cells & & & \\
US & 227 & 131 & 53 & 328.3 \\
INT'L & 1111 & 729 & 401 & 177.1 \\
Global & 1338 & 860 & 454 & 194.7 \\
Cord blood & & & & \\
US & 151 & 147 & 47 & 221.3 \\
INT'L & 515 & 408 & 144 & 257.6 \\
Global & 666 & 555 & 191 & 248.7 \\
Total, including "other" & & & \\
US & 1284 & 865 & 290 & 342.8 \\
INT'L & 4180 & 3097 & 1392 & 200.3 \\
Global & 5464 & 3962 & 1682 & 224.9 \\
\hline
\end{tabular}

The number of patients reported to receive transplantation through the source of bone marrow, peripheral stem cells, cord blood, or other stem cell sources in 2021, 2018, and 2013 accounting for diagnosed patients receiving IgG, annual estimated savings to the healthcare system is remarkable, at $\$ 87,888$. Although assigning a dollar amount to a life is impossible, four agencies determined that amount to be $\$ 9.7$ million, by considering certain factors that contribute to society including productivity, spending, healthcare costs, and taxes [31]. This estimate assumes a lifespan of 70 years on average with a value of $\$ 135,714$ per year. These cost savings emphasize the critical need for early and accurate diagnosis and appropriate treatment, which ultimately lead to improved outcomes and lives saved.

National health spending in the US from 2019 to 2028 is expected to rise at a $5.4 \%$ average annual rate, reaching $\$ 6.2$ trillion [32]. Individual spending rose at a $4.3 \%$ average annual rate between 2014 and 2018 [23]. Notably, costs were restrained by utilization of outpatient care and a growing proportion of the US population receiving coverage through the Affordable Care Act. Importantly, the economic impacts were determined to be even greater than our previous estimates in a study assessing the economic effect of infections in PI patients obtaining

Table 11 Stem cell source used for patients having received HSCT by region

\begin{tabular}{lcccccccccc}
\hline Stem cell source & US & Canada & Latin America & West Europe & East Europe & Middle East & Asia & Australia & Africa & Global totals \\
\hline Bone marrow & 794 & 217 & 185 & 1374 & 307 & 290 & 103 & 30 & 33 & 3333 \\
Peripheral stem cells & 227 & 56 & 62 & 508 & 196 & 190 & 64 & 1 & 34 & 1338 \\
Cord blood & 151 & 72 & 78 & 196 & 23 & 42 & 93 & 8 & 3 & 666 \\
Other & 112 & 1 & 0 & 7 & 6 & 0 & 1 & 0 & 0 & 127 \\
Totals & 1284 & 346 & 325 & 2085 & 532 & 522 & 261 & 39 & 70 & 5464 \\
\hline
\end{tabular}

The number of patients reported to receive transplantation through the source of bone marrow, peripheral stem cells, cord blood, or other stem cell sources by region, 2021

Table 12 Patient gender and age

\begin{tabular}{|c|c|c|c|c|c|c|c|c|}
\hline & \multicolumn{3}{|l|}{2021} & \multicolumn{3}{|l|}{2018} & \multicolumn{2}{|l|}{2013} \\
\hline & US & INT'L & Global & US & INT'L & Global & Global & $\%$ change $(\%)$ \\
\hline \multicolumn{9}{|l|}{ Gender } \\
\hline Male & 7334 & 28,627 & 35,961 & 6085 & 19,790 & 25,875 & 3540 & 915.8 \\
\hline Female & 5695 & 20,389 & 26,084 & 4763 & 13,944 & 18,707 & 2803 & 830.6 \\
\hline Total & 13,029 & 49,016 & 62,045 & 10,848 & 33,734 & 44,582 & 6343 & 878.2 \\
\hline \multicolumn{9}{|l|}{ Age } \\
\hline$<1$ year & 958 & 3148 & 4106 & 672 & 2211 & 2883 & 149 & 2655.7 \\
\hline $1-4$ years & 2712 & 7641 & 10,353 & 1797 & 4987 & 6784 & & \\
\hline 5-19 years & 5196 & 16,431 & 21,627 & 3894 & 11,366 & 15,260 & & \\
\hline Total pediatric & 8866 & 27,220 & 36,086 & 6363 & 18,564 & 24,927 & & \\
\hline 20-39 years & 1769 & 7161 & 8930 & 2042 & 5855 & 7897 & & \\
\hline$\geq 40$ years & 3287 & 7884 & 11,171 & 2092 & 4111 & 6203 & & \\
\hline Total adult & 5056 & 15,045 & 20,101 & 4134 & 9966 & 14,100 & & \\
\hline Grand total & 13,922 & 42,265 & 56,187 & 10,497 & 28,530 & 39,027 & 5993 & 837.5 \\
\hline
\end{tabular}

The number of patients by age and gender in the United States and internationally in 2021, 2018, and 2013 
Table 13 PI post-diagnosis average annual estimated savings with and without lgG

\begin{tabular}{|c|c|c|c|c|c|c|}
\hline Condition & $\begin{array}{l}\text { Pre Dx average } \\
\text { no. of episodes }\end{array}$ & $\begin{array}{l}\text { Post Dx average } \\
\text { no. of episodes }\end{array}$ & Cost per episode & $\begin{array}{l}\text { Pre Dx } \\
\text { annual } \\
\text { cost }\end{array}$ & $\begin{array}{l}\text { Post Dx } \\
\text { annual } \\
\text { cost }\end{array}$ & $\begin{array}{l}\text { Post Dx average } \\
\text { annual savings }\end{array}$ \\
\hline Persistent otitis media & 4.2 & 1.6 & $\$ 607$ & $\$ 2549$ & $\$ 971$ & $\$ 1578$ \\
\hline Serious sinus and upper respiratory infections & 4.6 & 2.1 & $\$ 1125$ & $\$ 5175$ & $\$ 2362$ & $\$ 2813$ \\
\hline Viral infections & 3.7 & 1.4 & $\$ 2038$ & $\$ 7540$ & $\$ 2853$ & $\$ 4687$ \\
\hline Acute bronchitis & 3.1 & 0.8 & $\$ 468$ & $\$ 1450$ & $\$ 374$ & $\$ 1076$ \\
\hline Bacterial pneumonias & 2.8 & 0.6 & $\$ 4748$ & $\$ 13,294$ & $\$ 2848$ & $\$ 10,446$ \\
\hline $\begin{array}{l}\text { Chronic obstructive pulmonary disease and } \\
\text { bronchiectasis }\end{array}$ & 4.3 & 1.4 & $\$ 2136$ & $\$ 9184$ & $\$ 2990$ & $\$ 6194$ \\
\hline Hospitalization days & 19.8 & 3.1 & $\$ 2607$ & $\$ 51,618$ & $\$ 8081$ & $\$ 43,537$ \\
\hline Physician/ER visits & 70.8 & 11.7 & $\$ 367$ & $\$ 25,983$ & $\$ 4293$ & $\$ 21,690$ \\
\hline Days on antibiotics & 166.2 & 72.8 & $\$ 5$ & $\$ 831$ & $\$ 364$ & $\$ 467$ \\
\hline School/work days missed & 33.9 & 8.9 & $\$ 200$ & $\$ 6780$ & $\$ 1780$ & $\$ 5000$ \\
\hline Total per patient without lgG & & & & $\$ 124,404$ & $\$ 26,916$ & $\$ 97,488$ \\
\hline $\begin{array}{l}\text { Total per patient treated with lgG [impact of } \\
\text { lgG treatment weighted for } 32 \% \text { of identified } \\
\text { patients in database (average annual cost of } \\
\text { lgG }(\$ 30,000) \times 32 \%)]\end{array}$ & & & & $\$ 124,404$ & $\$ 36,516$ & $\$ 87,888$ \\
\hline
\end{tabular}
$\lg G$

IVIG therapy [33]. Cost-effective strategies in all aspects of healthcare, from diagnosis to treatment, are imperative to reduce the economic burden on individuals and the healthcare system.

\section{JMF initiatives}

SPIRIT $^{\circledR} \quad$ (Software for Primary Immunodeficiency Recognition, Intervention, and Tracking) Analyzer was developed by JMF as a cost-effective strategy to further expedite the early diagnosis of patients with PI. The SPIRIT ${ }^{\circledR}$ Analyzer identifies at-risk patients by matching 352 ICD-10 codes to JMF's 10 Warning Signs of PI (Figs. 1, 2). The software analyzes over one million claims per hour in large existing datasets and establishes low-, medium-, and high-risk categories by calculating risk points. It also uses current National Drug Pharmacy and Healthcare Common Procedure codes and data on dosage and frequency to calculate antibiotic use risk scores. The software was recently used prospectively in a contained health care coverage system [34] and is made available to providers and healthcare insurance companies as a public service by JMF. The SPIRIT ${ }^{\circledR}$ Analyzer provides an opportunity to notify providers of patients at risk for having a PI. These at-risk patients can then ideally obtain timely access to appropriate assessment, which ultimately leads to shortened time to diagnoses, improved outcomes and QOL. This early identification of patients with PI is predicted to be associated with considerable healthcare cost savings and the JMF is hopeful for increased utilization of this tool.
The initiation of SCID newborn screening programs, improvements in diagnostics, and advancements in genomic technologies over the past few decades have allowed for better prevalence estimates and have resulted in improved comprehension of PI and the causal mechanisms leading to monogenic defects of the immune system. To further improve diagnostics, and therefore our overall understanding of PI and its prevalence, JMF's Physician Algorithm: 4 Stages of Testing for PI has recently been updated in 2021, as seen in Fig. 9. However, there are still many undiscovered PIs. More of these causative defects will be discovered through further investigation of gene candidates and with the advancement of NGS technologies, which will improve our comprehension of disease mechanisms and of the immune system overall [35]. It is vital that global access advances at equal pace with these genetic technologies, to limit diagnostic inequalities.

Suspected PI patients with no genetic diagnosis often undergo a costly, time-consuming, and arduous diagnostic odyssey, delaying proper disease management and treatment, prolonging suffering, and decreasing QOL. NGS, which can mitigate this diagnostic odyssey, is unfortunately frequently unobtainable due to cost and inaccessibility. In 2019, to address the issue of accessibility and contribute to the advancement of these technologies, JMF initiated a free NGS pilot program for JMCN patients clinically diagnosed with a PI [36], which aimed to identify a specific defect, providing medical professionals a 


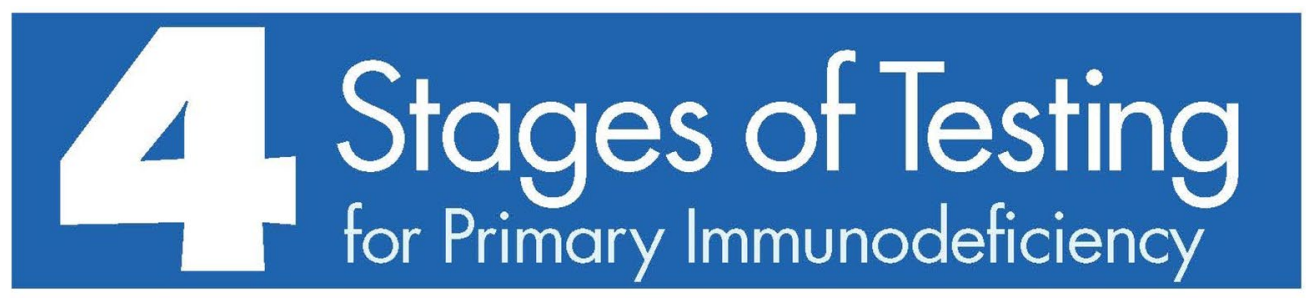

- History and physical examination

- $\mathrm{CBC}$ and differential

- Quantitative Immunoglobulin levels $\lg G, \lg M, \lg A$

- Specific antibody responses (tetanus, diphtheria, pneumococcus)

- Lymphocyte surface markers CD3/CD4/CD8/CD19/CD56

- Lymphocyte proliferation studies (mitogen/antigen stimulation or skin delayed type hypersensitivity)

3 - Neutrophil oxidation burst (if indicated)

- Response to pneumococcal vaccine (for ages 3 and up)

- Primary Immunodeficiency gene sequencing panel

- Complement screening $\mathrm{CH} 50$, specific complement components, AH50

- Enzyme activity measurements (e.g., adenosine deaminase, purine nucleoside phosphorylase)

- Phagocyte studies (e.g., surface glycoproteins, mobility, phagocytosis)

- NK cytotoxicity studies

- Neo antigen response to test antibody production

- Other surface molecules for detailed immunophenotype (e.g., memory B cells, T/NK cell subpopulations)

- Specific protein levels (e.g., SAP, Perforin, WASp)

- Cytokine or other function receptor quantification

- IgG subclass analysis

- Genomic studies

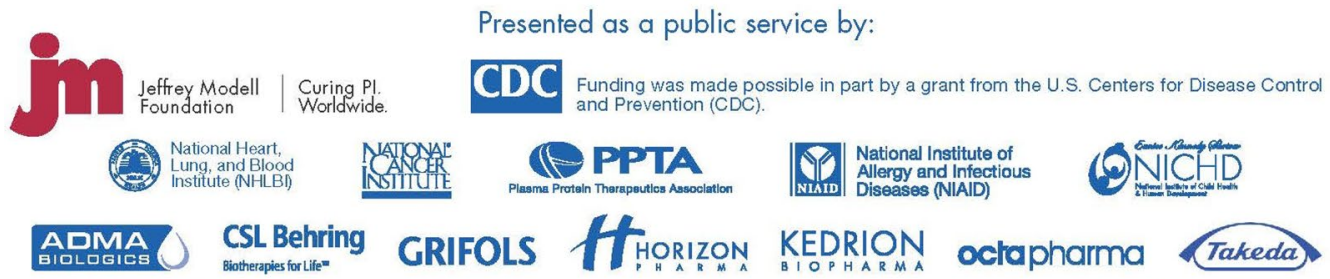

These warning signs were developed by the Jeffrey Modell Foundation Medical Advisory Board. Consultation with Primary Immunodeficiency experts is strongly suggested. (c) 2021 Jeffrey Modell Foundation For information or referrals, contact the Jeffrey Modell Foundation: info4pi.org

Fig. 9 Physician Algorithm: JMF's 4 stages of testing for PI

precise diagnosis for appropriate management and treatment, and highlight the value of PI NGS through the JMCN. Twenty-one JMCN sites, in 10 countries, were invited to participate. One hundred and fifty-eight patients were tested, using a commercially available PI NGS panel, which included 207 genes at the time, and
$21 \%$ received a molecular diagnosis. Through NGS, clinical diagnosis, disease management, treatment, and genetic counseling were altered in a substantial number of patients. Importantly, nearly half of the patients experienced a change in outcomes and there was an available therapy for nearly all diagnosed patients. This 
pilot [36] demonstrated the cost-efficiency, utility, and critical importance of NGS for PI.

Building on the success of the pilot program, JMF rolled this program out globally in early 2020, offering the entire JMCN an opportunity to participate. The gene panel was expanded from 207 to 407 genes, representing 95\% of the PI genes recognized by the IUIS. The program is ongoing, and critical feedback is being collected to further assess access challenges and impact on disease management and treatment. The program has been impactful thus far, and we are enthusiastic about its continuing success as we look to expand access beyond the JMCN globally. We believe the initiative showcases the impact, importance, and necessity of NGS for suspected PI patients, as well as the benefit of a true network of expert immunologists.

With the continued advancement of molecular technology, genome sequencing is becoming more common [37]. The resulting increasing numbers of medically actionable genotypes are driving the concept of "personalized medicine". As this technology advances, rare genotypes will be identified and known genotypes will be "immunophenotypically" expanded [37]. Soon, the complete genomes of newborns could be routinely sequenced [38], offering unprecedented insight into and foresight for a variety of health conditions including those of the immune system.

At present, 450 PI defects have been identified [2, 17, 39]. Over the last 5 years, at least 100 new genes were discovered by investigators within the JMCN, through molecular diagnosis, genetic sequencing, and advanced immunobiological investigations. The JMCN and its member physicians and investigators have continued to advance toward novel cures, including innovations in re-programming SCID mutations in hematopoietic stem cells using CRISPR technology and genome editing [40], and Antiviral T cell immunotherapy [41, 42]. This comprehensive global analysis of physician-reported data on patients with PI demonstrates an increase in the diagnosis of numerous genotypes throughout the JMCN. In addition to providing the foundation for early diagnosis and appropriate treatments, the JMCN serves as a longstanding and growing platform for collaboration and cutting-edge research, with coordinated and open access to expert immunologists, to promote further meaningful advancements in the field of PI, including gene discovery $[10,14,43,44]$.

\section{Conclusions}

The JMCN has steadily and substantially grown for more than two decades and continues to meaningfully influence the global Immunology community. In addition to building an extensive global patient database, the expanding JMCN serves as a unique and critical resource, providing the infrastructure for earliest diagnosis, optimized treatments, and implementation of standard-of-care and best practices. The JMCN provides a much-needed platform that facilitates the education of physicians and patients, awareness initiatives, and research advances, through collaboration and connectivity, ultimately resulting in improved outcomes and QOL for patients with PI.

\begin{abstract}
Abbreviations
PI: Primary immunodeficiencies; IEl: Inborn error of immunity; SCID: Severe combined immunodeficiency; QOL: Quality of life; JMF: Jeffrey Modell Foundation; JMCN: Jeffrey Modell Centers Network; IUIS: International Union of Immunological Societies; NGS: Next generation sequencing; OMIM: Online Mendelian inheritance in man; HSCT: Hematopoietic stem cell transplantation; HIPAA: Health Insurance Portability and Accountability Act; ER: Emergency room; AHRQ: Agency for healthcare research and quality; MEPS: Medical Expenditure Panel Survey; AHA: American Hospital Association; HCCl: Health Care Cost Institute; HCUP: Hospital Cost and Utilization Project; US: United States; CVID: Common variable immunodeficiency; IgG: Immunoglobulin therapy; SCIG: Subcutaneous immunoglobulin therapy; IVIG: Intravenous immunoglobulin therapy; PEG-ADA: Polyethylene glycol-conjugated adenosine deaminase; MRD: Matched related donor; MUD: Matched unrelated donor; mMUD: Mismatched unrelated donor; SPIRIT: Software for primary immunodeficiency recognition, intervention, and tracking; ICD: International classification of diseases; CRISPR: Clustered regularly interspaced short palindromic repeats.
\end{abstract}

\section{Supplementary Information}

The online version contains supplementary material available at https://doi. org/10.1186/s13223-022-00662-6.

Additional file 1: Figure S1. 2020-2021 Global Survey on Primary Immunodeficiencies. A survey developed by JMF for members of the JMCN following the most recent Classification of PI from the IUIS Expert Committee.

Additional file 2: Table S1. Percentage of Missing Responses by Variable. The percentage of missing responses by variable, which ranges from 0.0 to $97.3 \%$ ( $n=300)$. Variables correspond to the 2020-2021 Global Survey on Primary Immunodeficiencies. To note, for all variables other than demographics, a missing response was interpreted as a "zero" in that the physician did not have any patients having that particular condition or receiving that particular treatment.

\section{Acknowledgements}

The authors thank the members of the Jeffrey Modell Centers Network for their constant support and unwavering dedication to the Jeffrey Modell Foundation and the global primary immunodeficiency community. We thank Dr. Chaim Roifman, Founder and Director of the Jeffrey Modell Centers Network, for his vision. We thank Invitae for a productive partnership and impactful collaboration.

\section{Authors' contributions}

All authors substantially contributed to the conception and design of the work. JQ acquired, analyzed, and interpreted the data and was a major contributor in writing the manuscript. JO contributed substantial revisions to the manuscript. VM and FM provided manuscript revisions. All authors read and approved the final manuscript.

Funding

Not applicable. 


\section{Availability of data and materials}

Not applicable; all data used for this analysis are included in this published article.

\section{Declarations}

Ethics approval and consent to participate

Not applicable.

\section{Consent for publication}

Not applicable.

\section{Competing interests}

The authors declare that they have no conflict of interest except for the following: Jordan Orange, MD, PhD: Consultant to Grifols, CSL, Takeda, Teva, Sobi, Jansen; ADMA and Gigagen Scientific Advisory Boards, author and editor in immunology for Up To Date receiving royalties.

Received: 18 October 2021 Accepted: 20 February 2022

Published online: 04 March 2022

\section{References}

1. National Institute of Allergy and Infectious Diseases. Primary immune deficiency diseases. https://www.niaid.nih.gov/diseases-conditions/ primary-immune-deficiency-diseases-pidds. Accessed 3 May 2021.

2. Bousfiha A, Jeddane L, Picard C, et al. Human inborn errors of immunity: 2019 update of the IUIS phenotypical classification. J Clin Immunol. 2020;40:66-81. https://doi.org/10.1007/s10875-020-00758-x.

3. Tangye SG, Al-Herz W, Bousfiha A, et al. The ever-increasing array of novel inborn errors of immunity: an interim update by the IUIS Committee. J Clin Immunol. 2021;41:666-79. https://doi.org/10.1007/ s10875-021-00980-1.

4. Cunningham-Rundles C, Ponda PP. Molecular defects in T- and B cell primary immunodeficiency diseases. Nat Rev Immunol. 2005;5:880-92.

5. Cooper MA, Pommering TL, Koranyi K. Primary immunodeficiencies. Am Fam Physician. 2003;68:2001-8.

6. Carneiro-Sampaio M, Coutinho A. Early-onset autoimmune disease as a manifestation of primary immunodeficiency. Front Immunol. 2015;6:185. https://doi.org/10.3389/fimmu.2015.00185.

7. Reust CE. Evaluation of primary immunodeficiency disease in children. Am Fam Physician. 2013;87(11):773-8.

8. Boyle JM, Buckley RH. Population prevalence of diagnosed primary immunodeficiency diseases in the United States. J Clin Immunol. 2007;27(5):497-502.

9. Bousfiha AA, Jeddane L, Ailal F, Benhsaien I, Mahlaoui N, Casanova JL, et al. Primary immunodeficiency diseases worldwide: more common than generally thought. J Clin Immunol. 2013;33(1):1-7.

10. Stray-Pedersen A, Sorte HS, Samarakoon P, Gambin T, Chinn IK, Coban Akdemir ZH, et al. Primary immunodeficiency diseases: genomic approaches delineate heterogeneous Mendelian disorders. J Allergy Clin Immunol. 2017;139(1):232-45. https://doi.org/10.1016/j.jaci.2016.05.042.

11. Rider NL, Kutac C, Hajjar J, Scalchunes C, Seeborg FO, Boyle M, et al. Health-related quality of life in adult patients with common variable immunodeficiency disorders and impact of treatment. J Clin Immunol. 2017;37(5):461-75. https://doi.org/10.1007/s10875-017-0404-8.

12. Quinti I, Di Pietro C, Martini H, Pesce AM, Lombardi F, Baumghartner M, et al. Health related quality of life in common variable immunodeficiency. Yonsei Med J. 2012;53(3):603-10. https://doi.org/10.3349/ymj.2012.53.3. 603.

13. Casanova JL, Abel L, Quintana-Murci L. Immunology taught by human genetics. Cold Spring Harb Symp Quant Biol. 2013;78:157-72. https://doi. org/10.1101/sqb.2013.78.019968.

14. Meyts I, Bosch B, Bolze A, Boisson B, Itan Y, Belkadi A, et al. Exome and genome sequencing for inborn errors of immunity. J Allergy Clin Immunol. 2016;138(4):957-69. https://doi.org/10.1016/j.jaci.2016.08.003.

15. Modell V, Gee B, Lewis DB, Orange JS, Roifman CM, Routes JM, et al. Global study of primary immunodeficiency diseases (PI)_diagnosis, treatment, and economic impact: an updated report from the Jeffrey Modell Foundation. Immunol Res. 2011;51:61-70.

16. Modell F, Puente D, Modell V. From genotype to phenotype. Further studies measuring the impact of a physician education and public awareness campaign on early diagnosis and management of primary immunodeficiencies. Immunol Res. 2009;44(1-3):132-49.

17. Tangye SG, Al-Herz W, Bousfiha A, et al. Human inborn errors of immunity: 2019 update on the classification from the International Union of Immunological Societies Expert Committee. J Clin Immunol. 2020;40:2464. https://doi.org/10.1007/s10875-019-00737-x.

18. Picard C, Gaspar BH, Al-Herz W, Bousfiha A, Casanova JL, Chatila T, et al. International Union of Immunological Societies: 2017 primary immunodeficiency diseases committee report on inborn errors of immunity. J Clin Immunol. 2018;38(1):96-128. https://doi.org/10.1007/ s10875-017-0464-9.

19. Modell V, Orange JS, Quinn J, et al. Global report on primary immunodeficiencies: 2018 update from the Jeffrey Modell Centers Network on disease classification, regional trends, treatment modalities, and physician reported outcomes. Immunol Res. 2018;66:367-80. https:// doi.org/10.1007/s12026-018-8996-5.

20. Modell V, Knaus M, Modell F, Roifman C, Orange J, Notarangelo LD. Global overview of primary immunodeficiencies: a report from Jeffrey Modell Centers worldwide focused on diagnosis, treatment, and discovery. Immunol Res. 2014;60(1):132-44. https://doi.org/10.1007/ s12026-014-8498-z

21. Agency for Healthcare Research and Quality. Number of people with care in thousands by condition, United States, 2016-2018. Medical Expenditure Panel Survey. https://meps.ahrq.gov/mepstrends/hc_cond_ icd10/. Accessed 28 Apr 2021.

22. Kaiser Family Foundation. Hospital adjusted expenses per inpatient day. https://www.kff.org/health-costs/state-indicator/expenses-per-inpat ient-day/?currentTimeframe=0\&sortModel=\%7B\%22colld\%22:\%22Loc ation\%22,\%22sort\%22:\%22asc\%22\%7D. Accessed 5 May 2021.

23. Health Care Cost Institute (HCCl) 2018 Health Care Cost and Utilization Report. 2018. https://healthcostinstitute.org/images/pdfs/HCCI_2018_ Health_Care_Cost_and_Utilization_Report.pdf. Accessed 3 May 2021.

24. United States Social Security Administration. Average and median amounts of net compensation. https://www.ssa.gov/oact/cola/central. html. Accessed 3 May 2021.

25. Agency for Healthcare Research and Quality (AHRQ). Healthcare Cost and Utilization Project (HCUP). https://hcupnet.ahrq.gov/\#setup. Accessed 3 May 2021.

26. Abolhassani H, Azizi G, Sharifi L, et al. Global systematic review of primary immunodeficiency registries. Expert Rev Clin Immunol. 2020;16(7):71732. https://doi.org/10.1080/1744666X.2020.1801422.

27. Hadizadeh H, Salehi M, Khoramnejad S, Vosoughi K, Rezaei N. The association between parental consanguinity and primary immunodeficiency diseases: a systematic review and meta-analysis. Pediatr Allergy Immunol. 2017;28(3):280-7. https://doi.org/10.1111/pai. 12685.

28. Cunningham-Rundles C, Bodian C. Common variable immunodeficiency: clinical and immunological features of 248 patients. Clin Immunol. 1999:92(1):34-48

29. Chapel $\mathrm{H}$, Cunningham-Rundles $\mathrm{C}$. Update in understanding common variable immunodeficiency disorders (CVIDs) and the management of patients with these conditions. Br J Haematol. 2009;145(6):709-27. https://doi.org/10.1111/j.1365-2141.2009.07669.x.

30. de la Morena MT, Leonard D, Torgerson TR, Cabral-Marques O, Slatter M, Aghamohammadi A, et al. Long-term outcomes of 176 patients with X-linked hyper-lgM syndrome treated with or without hematopoietic cell transplantation. J Allergy Clin Immunol. 2017;139(4):1282-92. https://doi. org/10.1016/j.jaci.2016.07.039.

31. Merrill D. No one values your life more than the federal government. Manhattan: Bloomberg; 2021

32. Centers for Medicare and Medicaid Services. National health expenditure data. https://www.cms.gov/Research-Statistics-Data-and-Systems/Stati stics-Trends-and-Reports/NationalHealthExpendData/NHE-Fact-Sheet. Accessed 3 May 2021.

33. Menzin J, Sussman M, Munsell M, Zbrozek A. Economic impact of infections among patients with primary immunodeficiency disease receiving IVIG therapy. Clinicoecon Outcomes Res. 2014;6:297-302. 
34. Rider NL, Miao D, Dodds M, Modell V, Modell F, Quinn J, Schwarzwald H, Orange JS. Calculation of a primary immunodeficiency "Risk Vital Sign" via population-wide analysis of claims data to aid in clinical decision support. Front Pediatr. 2019;7:70. https://doi.org/10.3389/fped.2019.00070.

35. Milner JD, Holland SM. The cup runneth over: lessons from the everexpanding pool of primary immunodeficiency diseases. Immunology. 2013;13:635-48.

36. Quinn J, Modell V, Holle J, et al. Jeffrey's insights: Jeffrey Modell Foundation's global genetic sequencing pilot program to identify specific primary immunodeficiency defects to optimize disease management and treatment. Immunol Res. 2020;68:126-34. https://doi.org/10.1007/ s12026-020-09131-X.

37. Sun J, Yang L, Lu Y, et al. Screening for primary immunodeficiency diseases by next-generation sequencing in early life. Clin Transl Immunol. 2020;9(5):e1138. https://doi.org/10.1002/cti2.1138.

38. Puck J. Laboratory technology for population-based screening for SCID in neonates: the winner is T-cell receptor excision circles (TRECs). J Allergy Clin Immunol. 2012;129(3):607-16. https://doi.org/10.1016/j.jaci.2012.01. 032.

39. Bharat ST, Alizadehfar R, Desrosiers M, Shuster J, Pant N, Tsoukasa CM. Adult primary immune deficiency: what are we missing? Am J Med. 2012;125(8):779-86.

40. Pollack A. Jennifer Doudna, a pioneer who helped simplify genome editing. Profiles in science, NY Times. 2015. https://www.nytimes.com/ 2015/05/12/science/jennifer-doudna-crispr-cas9-genetic-engineering. html. Accessed 3 May 2021.

41. Keller MD, Bollard CM, Hanley PJ, McCormack S, Heimall J, Bunin N, et al. Viral-specific T lymphocytes for treatment of viral infections in primary immunodeficiency. Biol Blood Marrow Trans. 2015;21(2):S229-30.

42. Naik S, Nicholas SK, Martinez CA, Leen AM, Hanley PJ, Gottschalk SM, et al. Adoptive immunotherapy for primary immunodeficiency disorders with virus-specific T lymphocytes. J Allergy Clin Immunol. 2016;137(5):14981505.e1. https://doi.org/10.1016/j.jaci.2015.12.1311.

43. Maffucci P, Filion CA, Boisson B, Itan Y, Shang L, Casanova JL, et al. Genetic diagnosis using whole exome sequencing in common variable immunodeficiency. Front Immunol. 2016;7:220. https://doi.org/10.3389/ fimmu.2016.00220.eCollection2016.

44. Abolhassani H, Chou J, Bainter W, Platt CD, Tavassoli M, Momen T, et al. Clinical, immunologic, and genetic spectrum of 696 patients with combined immunodeficiency. J Allergy Clin Immunol. 2017;141:1450-8. https://doi.org/10.1016/j.jaci.2017.06.049.

\section{Publisher's Note}

Springer Nature remains neutral with regard to jurisdictional claims in published maps and institutional affiliations.

Ready to submit your research? Choose BMC and benefit from:

- fast, convenient online submission

- thorough peer review by experienced researchers in your field

- rapid publication on acceptance

- support for research data, including large and complex data types

- gold Open Access which fosters wider collaboration and increased citations

- maximum visibility for your research: over $100 \mathrm{M}$ website views per year

At BMC, research is always in progress.

Learn more biomedcentral.com/submissions 